\title{
Rescue System with Health Condition Monitoring Together with Location and Attitude Monitoring as Well as the Other Data Acquired with Mobile Devices
}

\author{
Kohei Arai ${ }^{1}$ \\ 1 Graduate School of Science and Engineering \\ Saga University \\ Saga City, Japan
}

\author{
Taka Eguchi ${ }^{1}$ \\ 1 Graduate School of Science and Engineering \\ Saga University \\ Saga City, Japan
}

\begin{abstract}
Rescue system with health condition monitoring together with location and attitude monitoring as well as the other data acquired with mobile devices is proposed. Backup system for location estimation is also proposed. On behalf of GPS receivers and WiFi beacon receivers, ZigBee is used as a backup system. Attitude can be monitored with acceleration-meters equipped in the commercially available smart phones and iphones. Also, the number of steps and calorie consumptions can be monitored with the commercially available smart phones and i-phones. By using these body attached sensors, health condition of the persons who need a help for rescue when the emergency situations can be monitored and used for rescue planning and triage. Overall system configuration is proposed together with the detailed system descriptions with some of the experimental data.
\end{abstract}

Keywords-Rescue system; Location estimation; Attitude estimation; Health monitoring; Mobile applications; Triage; Rescue planning

\section{INTRODUCTION}

There are previously proposed methods and systems which allow physical health monitoring [1]-[5]. Most of previous methods and systems are not wearable and do not allow psychological status monitoring. The proposed physical and psychological health monitoring system is intended to monitor these five major vital signs. Instead of direct blood pressure measurement, indirect blood pressure measurement is proposed by using a created regressive equation with the measured body temperature, heart rate and the number of steps because it is hard to measure the blood pressure directly. Also, consciousness can be monitored by using acquired eye images and its surroundings on behalf of using EEG sensors, because EEG signals are used to be suffered from noises.

There are previously proposed evacuation and rescue methods and systems [6]-[8]. It may be possible to find that multi agent-based simulation makes it possible to simulate the human activities in rescue and evacuation process [9],[10]. A multi agent-based model is composed of individual units, situated in an explicit space, and provided with their own attributes and rules [11]. This model is particularly suitable for modeling human behaviors, as human characteristics can be presented as agent behaviors. Therefore, the multi agent-based model is widely used for rescue and evacuation simulation [9][13].
In this study, GIS map is used to model objects such as road, building, human, fire with various properties to describe the objects condition. With the help of GIS data, it enables the disaster space to be closer to a real situation [13]-[16].

A rescue model for people with disabilities in large scale environment is proposed. The proposed rescue model provides some specific functions to help disabled people effectively when emergency situation occurs. Important components of an evacuation plan are the ability to receive critical information about an emergency, how to respond to an emergency, and where to go to receive assistance. Triage is a key for rescue procedure. Triage can be done with the gathered physical and psychological data which are measured with a sensor network for vital sign monitoring. Through a comparison between with and without consideration of triage, it may be possible to find that the time required for evacuation from disaster areas with consideration triage is less than that without triage. The following section describes the proposed rescue system with triage followed by examples of the monitored data of health conditions together with the location of attitude monitoring. Then alternative location determination with ZigBee receiver and transmitter is described with some experimental data. Finally, conclusion is described together with some discussions.

\section{PROPOSED RESCUE SYSTEM}

\section{A. Basic Idea}

Fig.1 shows the concept of the proposed rescue system. There are three major components, persons who need a help for evacuation, Information Collection Center: ICC for health, traffic, and the other conditions together with the location and attitude information of the persons who need a help and the rescue peoples. Body attached sensors allow measurements of health conditions and the location and attitude of the persons who need a help. The measured data can be transmitted to the ICC through smart-phone, or i-phone, or tablet terminals of which the persons who need a help are carrying. By using the collected health condition and the location/attitude as well as traffic condition information, most appropriate rescue peoples are determined by the person by the person. It is better to consider a triage in the emergency rescue stages. Therefore, health condition monitor is necessary. Fig. 2 shows the proposed health condition monitoring system together with the acquired data transmission system. 


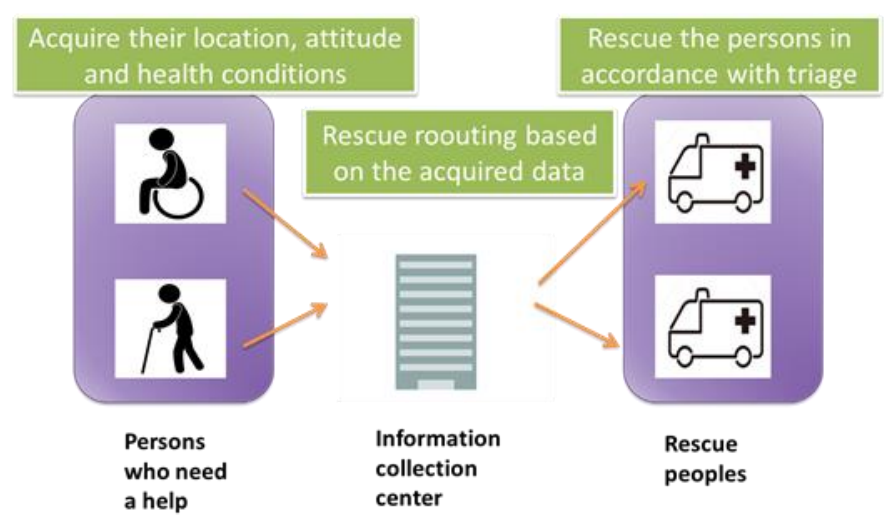

Fig. 1. Concept of the proposed rescue system

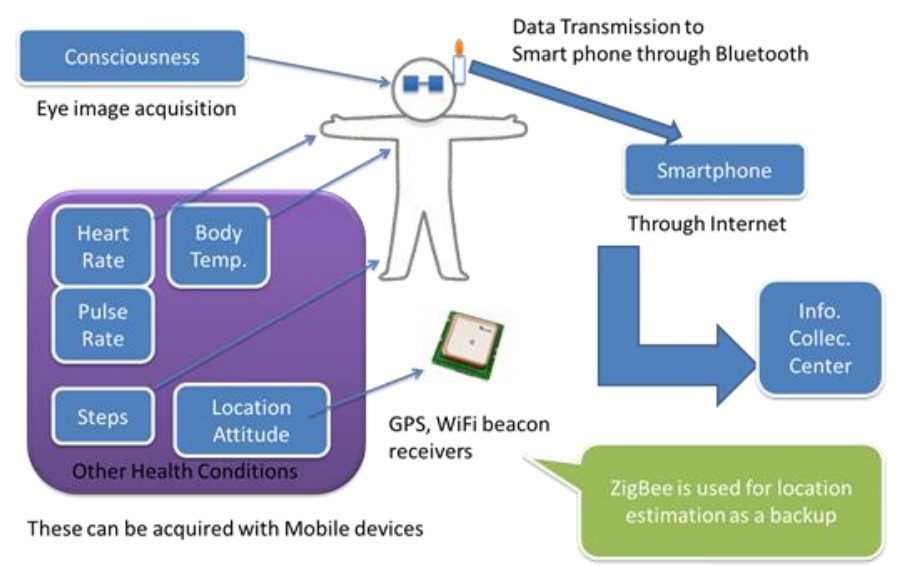

Fig. 2. Proposed health condition monitoring system together with the acquired data transmission system

\section{B. Sensors}

There are four major items of the vital signs for triage. Those are Body temperature, Blood pressure, Pulse rate, Number of blesses. Therefore, these four items are mandatory for triage. Other than these, Number of steps, calorie consumptions would be better to monitor together with the location and attitude as well as types of movement (walking, standing, sitting, laying, running, jumping, etc.). These data can be transmitted to the ICC through WiFi networks (Bluetooth for transmission from sensors to smart-phone and WiFi network for transmission from the smart-phone to ICC). Location measurement can be done with GPS receiver in the smart-phone and with WiFi beacon receiver is the same smartphone. The GPS receiver does not work indoor situation. Also, both GPS receiver and WiFi receiver based location determination accuracy is not good enough. Therefore, some of alternative method would be better to add to the rescue system. In this paper, ZigBee of transmitter and receiver is used for location determination as a backup as shown in Fig.2.

Outlooks of body attached sensors are shown $\mathrm{n}$ Fig.3.
(a)Pulse Rate
(b)Heart Rate
(c)Body
Temperature

(d)Blood Pressure (e)Step, Calorie Consumption, Location and Attitude can be measured with these sensors.

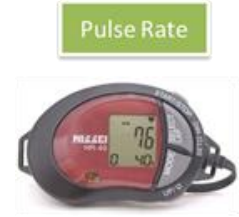

(a)Pulse Rate Blood Pressure

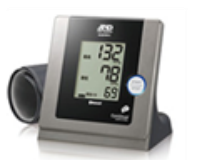

(d)Blood Pressure (e)Step, Calorie Consumption, Location and Attitude

Fig. 3. Used body attached sensors for health monitoring

\section{Triage}

In the triage stage, the types of disabilities which are shown in Table 1 are taken into account. Through a consideration of these types of disabilities, 10 grades of disabilities are taken into account in the triage.

\section{TABLE I. TYPES OF DISABILITY}

\begin{tabular}{|l|}
\hline Types of Disability \\
\hline Cognitive Disorder \\
\hline Neuropathy \\
\hline Movement Disorder \\
\hline Elderly Condition \\
\hline Hearing Loss \\
\hline Language, Visual Impairment \\
\hline
\end{tabular}

\section{Examples of Measured Data}

Other than smart-phone based step monitoring, there are some body attached step monitoring sensors. Fig. 4 shows an example of the step monitoring sensor. The sensor allows measurement not only the number of steps but also calorie consumption can be measured. Also, these measured data are archived and referred through Bluetooth communications. One of example of the archived steps and calorie consumption is shown in Fig.5.

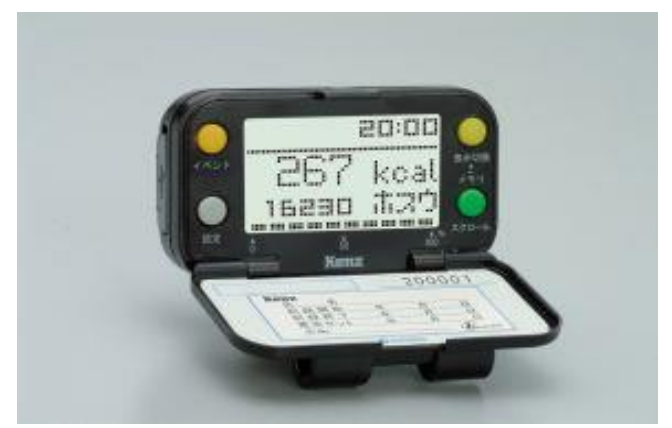

Fig. 4. Alternative step monitoring sensor 


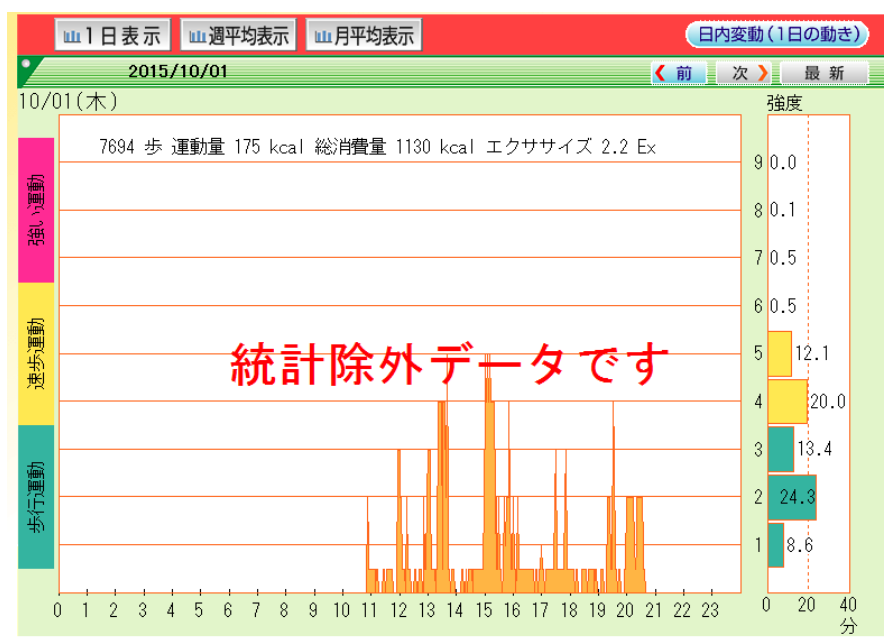

Fig. 5. Example of the acquired step data together with calorie consumption

Moreover, the number of steps can be measured with iphone application software tools. Fig.6 shows an example of the measures steps in a month with iOS8 of i-phone.

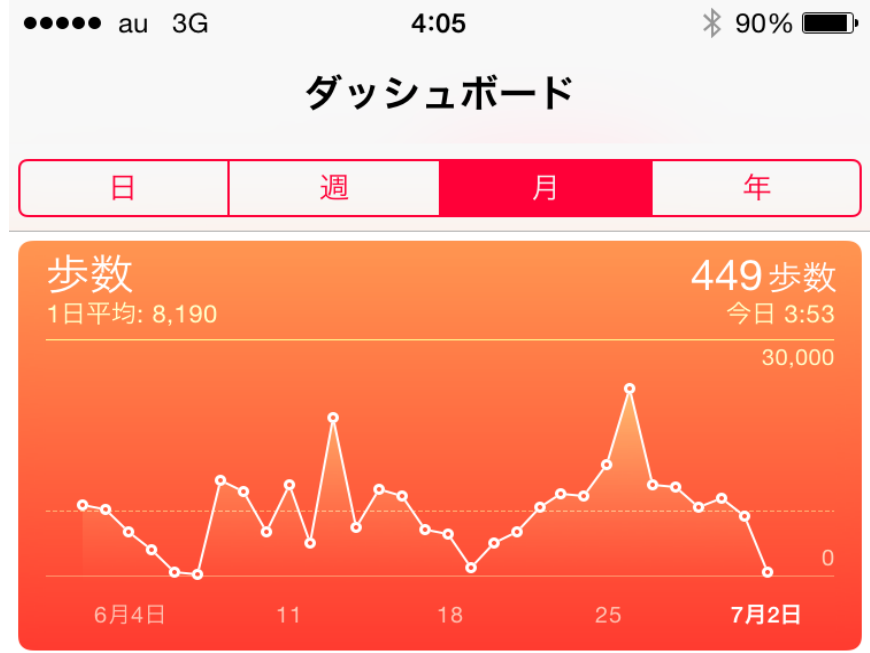

Fig. 6. Step monitoring with iOS8 of i-phone

There is health condition monitoring application software tool so called HealthKit under the iOS8. The menu of the HealthKit is shown in Fig.7.

\begin{tabular}{|c|c|c|c|c|}
\hline 8 & Vital & $>$ & & \\
\hline $\boldsymbol{\theta}$ & Fitness & $>$ & <Return Vital & \\
\hline${ }^{*}$ & Food & $>$ & Blood Pressure & $>$ \\
\hline 量 & Medical Check Results & $>$ & Number of Bless & $>$ \\
\hline ( & Personal ID & $>$ & Herat Rate & $>$ \\
\hline ாீ & Physical Check Results & $>$ & Body Temperature & $>$ \\
\hline
\end{tabular}

Fig. 7. Health condition monitoring with HealthKit with iOS8

Other than the vital records, Fitness, Food, Medical check results, physical check results, sleep quality and personal ID can be referred. Process flow of the proposed health monitoring system together with the acquired data transmission system is shown in Fig.8.

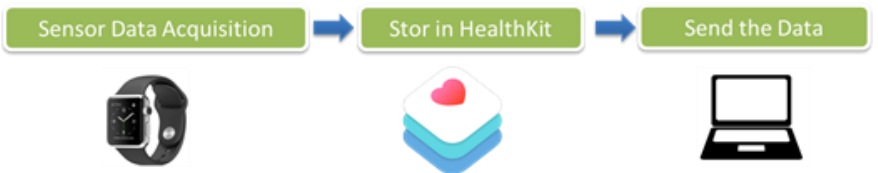

Fig. 8. Process flow of the proposed health monitoring system together with the acquired data transmission system

On the other hand, Android OS of smart-phone which is shown in Fig.9 provides API which allows the step count and step detector as shown in Fig.10. That is Android4.4kit-kat.

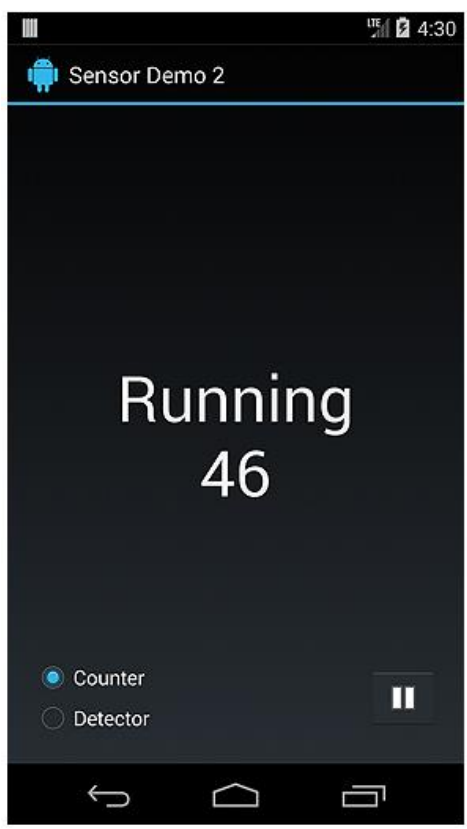

Fig. 9. Example of Android OS of smart-phone

\section{Android4.4 kitkat}

Steps can be get with Acceleration meter

- TYPE_STEP_COUNTER

Accumulated steps can be get

- TYPE_STEP_DETECTOR

Once step is acquired, send the data

It is available to send the steps in the time interval

Fig. 10. Additionally available APIs by using Android4.4kitkat

Using the API of Android4.4kit-kat together with acceleration meter, types of movements can be determined as shown in Fig.11. Also, identification of attitude type by using the difference between actual and reference power spectrum derived from acceleration meter is available as shown in Fig.12. 


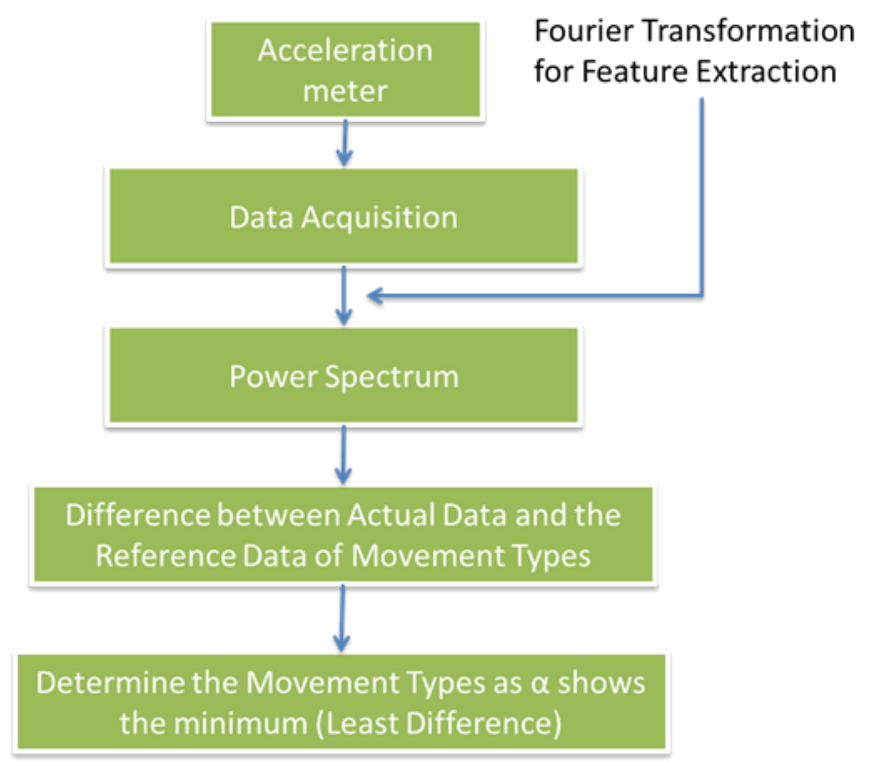

Fig. 11. Method for attitude detection

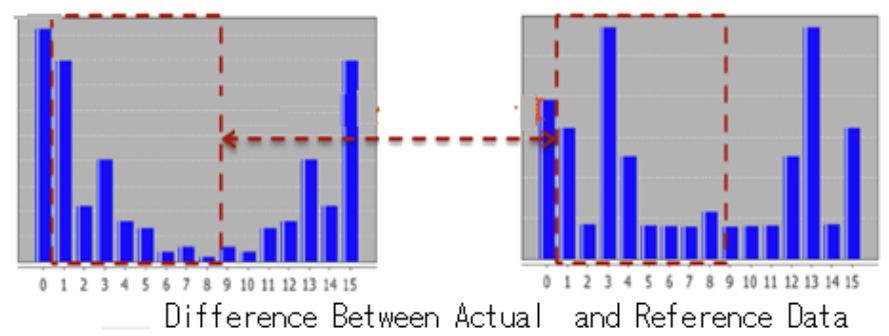

Fig. 12. Identification of attitude type by using the difference between actual and reference power spectrum derived from acceleration meter

Acquired acceleration meter data is compared to the previously acquired reference data of the designated several movement types in the frequency domain (Power spectrum). The frequency components between $a$ and $b$ are compared followed by the summation of the different between both, $a$ and $b$ calculation as shown in equation (1).

$$
\alpha=|a 2-b 2|+|a 3-b 3|+\cdots+|a 9-b 9|
$$

Thus movement types are discriminated. Also, movement types can be discriminated with ZigBee. Fig.13 shows outlook of the ZigBee used for the experiments. Movement types, in this case, can be identified as "Stop", "Begin to move" and "Freely falling down" as shown in Fig.14. One of the examples of the receiving signal for the movement type of the "Freely falling down" is shown in Fig.15 while that of the "Stop" on the floor is shown in Fig.16, respectively. Thus the movement types can be identified with receiving signal strength of ZigBee. Meanwhile, one of examples of the measured pulse rate with the Pulse Coach which is shown in Fig.3 (a) is shown in Fig.17. Pulse per minute can be measured every one second.

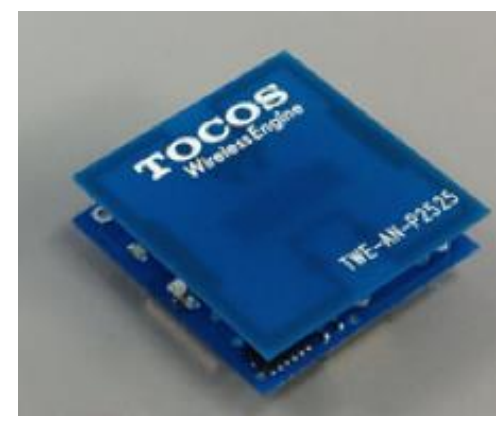

Fig. 13. Outlook of ZigBee

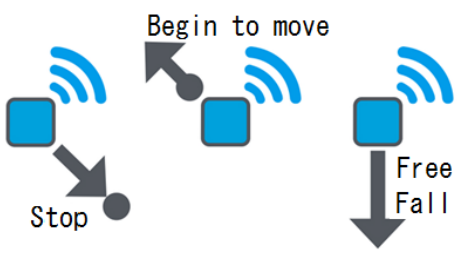

Fig. 14. Movement type identification with ZigBee

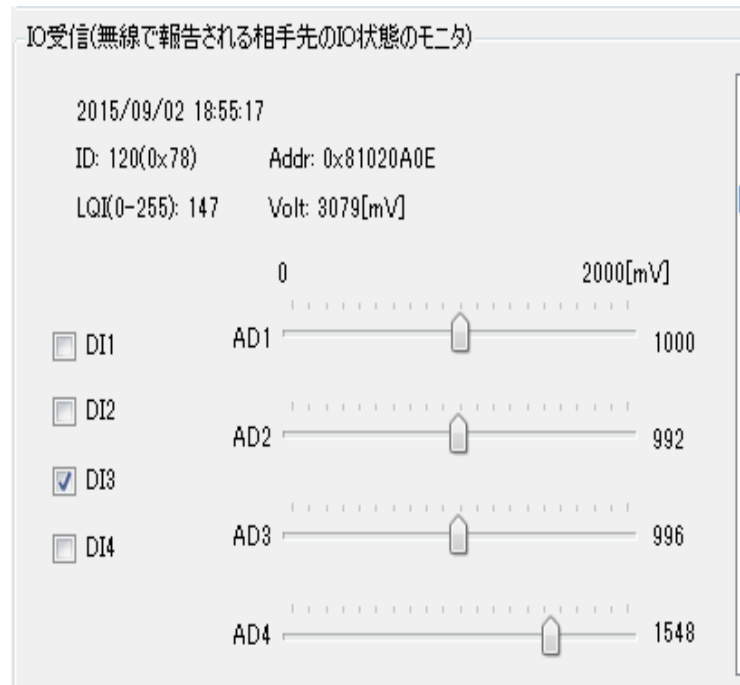

:788115013981020A0E001188000C0700000F3D3E4160F353 (2015/09/02 18:56:26) $788115013681020 \mathrm{~A} 0 \mathrm{E} 001178000 \mathrm{C} 0700010 \mathrm{~F} 403 \mathrm{C} 3 \mathrm{~F} 60 \mathrm{~F} 366$ (2015/09/02 18:56:23) :788115014281020A0E001170000C0700080F3E3D4360F 358 (2015/09/02 18:56:23) :78811501368 1020A0E001160000C0700080F3E3C4 160E981 (2015/09/02 18:55:18)

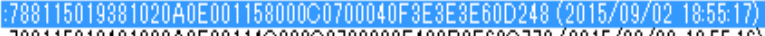
$7888115018481020 \mathrm{~A} 0 \mathrm{E} 00114 \mathrm{C} 000 \mathrm{CO} 0700000 \mathrm{~F} 403 \mathrm{~B} 3 \mathrm{E} 60 \mathrm{C} 773(2015 / 09 / 02$ 18:55:16) :788115016681020A0E001144000C0700080F 40393D60ED6E (2015/09/02 18:55:13) 788811501578 1020A0E00113C000C0700000F3F3A3C60E992 (2015/09/02 18:55:10) :788115016981020A0E001134000C0700000F 3 F 3A3C60F57C (2015/09/02 18:55:10)

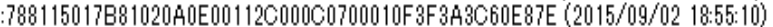
:788115017581020A0E001124000C0700000F 3E3C3E60E290 (2015/09/02 18:55:09)

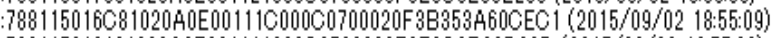
$788115018481020 \mathrm{~A} 0 \mathrm{E} 001114000 \mathrm{C} 0700080 \mathrm{~F} 3 \mathrm{~F} 3 \mathrm{C} 3 \mathrm{~B} 60 \mathrm{D} 09 \mathrm{D}(2015 / 09 / 02$ 18:55:08) :788115017881020A0E00110C000C0700000F3E3A3C60FB90 (2015/09/02 18:55:00) $788115017281020 \mathrm{~A} 0 \mathrm{E} 001104000 \mathrm{C} 0700000 \mathrm{~F} 3 \mathrm{~F} 3 \mathrm{~A} 3 \mathrm{C} 6 \mathrm{OOF} 8 \mathrm{AO}$ (2015/09/02 18:54:59) $788115016 \mathrm{~F} 81020 \mathrm{~A} 0 \mathrm{E} 0010 \mathrm{FC} 000 \mathrm{C} 0700020 \mathrm{~F} 42393160 \mathrm{~F} 8 \mathrm{~B} 3$ (2015/09/02 18:54:58) 7888115016F81020A0E0010F4000C0700080F3E393EG0DBCg (2015/09/02 18:54:58) :788115016381020A0E0010EC000C0700000F3F3A3D60C8F 7 (2015/09/02 18:54:56) $788115016 C 81020 \mathrm{~A} 0 \mathrm{E} 00010 \mathrm{E} 4000 \mathrm{C} 0700000 \mathrm{~F} 3 \mathrm{~F} 3 \mathrm{~A} 3 \mathrm{D} 60 \mathrm{D} 8 \mathrm{E} 6 \mathrm{C}$ (2015/09/02 18:54:54) $788115016681020 \mathrm{~A} 0 \mathrm{E} 0010 \mathrm{DC} 000 \mathrm{C} 0700010 \mathrm{~F} 3 \mathrm{E} 3 \mathrm{~B} 3 \mathrm{C} 60 \mathrm{~F} 3 \mathrm{Dg}$ (2015/09/02 18:54.53) $788115016 C 81020 \mathrm{AOOE} 001004000 \mathrm{C} 0700000 \mathrm{~F} 33 \mathrm{~A} 3 \mathrm{D} 60 \mathrm{FAD} 5$ (2015/09/02 18:54:53) $788115017581020 \mathrm{~A} 0 \mathrm{E} 0010 \mathrm{CC} 000 \mathrm{C} 0700010 \mathrm{~F} 3 \mathrm{E} 3 \mathrm{C} 3 \mathrm{~B} 60 \mathrm{FDDO}(2015 / 0 \mathrm{~g} / 02$ 18:54:52)

Fig. 15. Example of the receiving signal from the ZigBee when it is falling freely (DI3) 


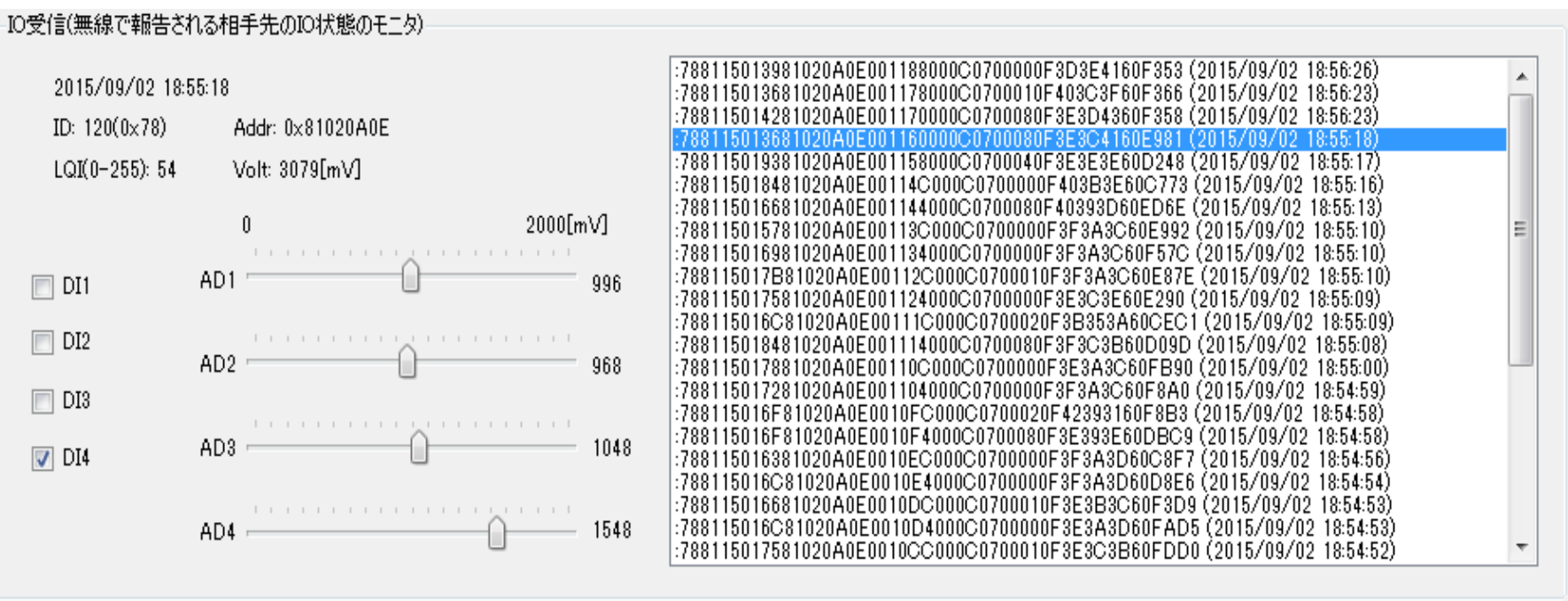

Fig. 16. Example of the receiving signal from the ZigBee when it is on the floor (DI4)

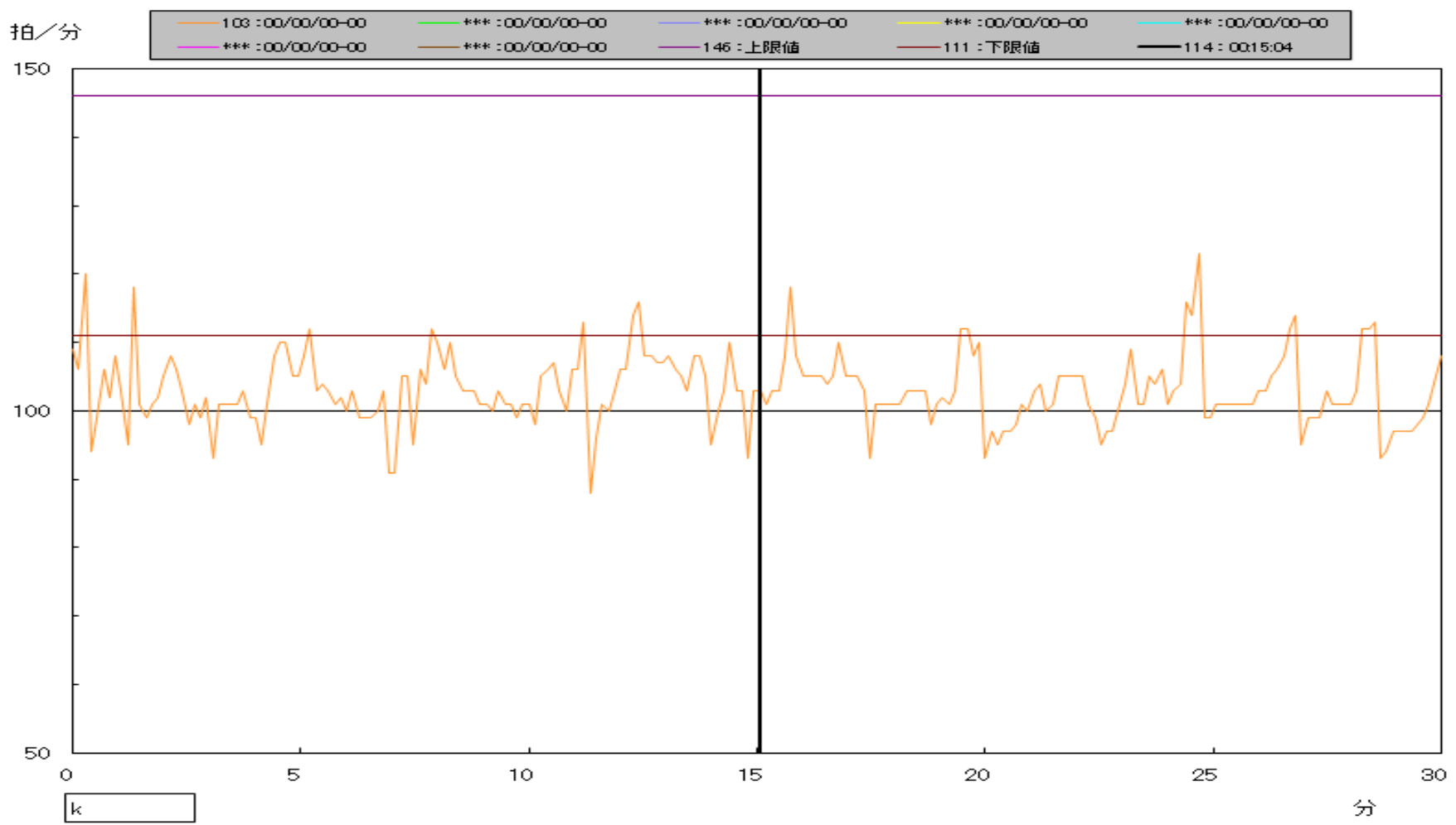

Fig. 17. Example of Pulse Rate measured data (1/minute)

\section{Distance MEasurements With Zigbee}

\section{A. Basic Idea}

ZigBee coverage is limited up to around $100 \mathrm{~m}$. Therefore, the location of the ZigBee receiver can be identified from the surrounding three ZigBee transmitters as shown in Fig.18. Also, one pair of ZigBee transmitter and receiver makes distance measurements with signal strength. Also, ZigBee coverage can be expanded with through repeaters as shown in Fig.19.

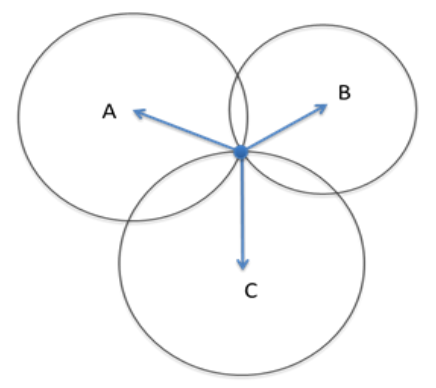

Fig. 18. Location determination concept with three ZigBee stations 


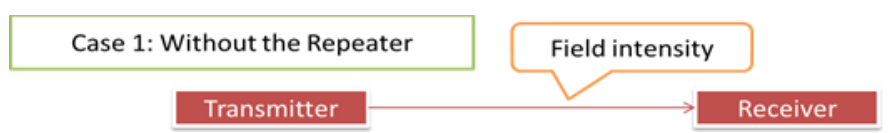

(a)Without repeater

Case 2: There is the Repeater

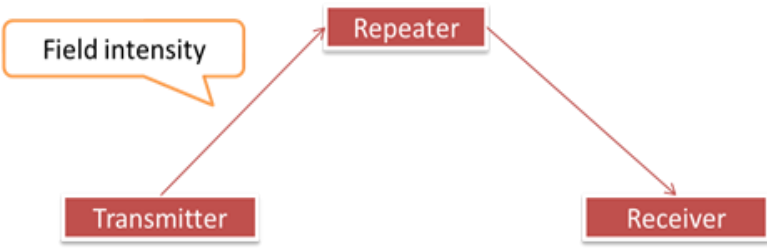

(b)With repeater

Fig. 19. Distance measurements

\section{B. Measurement Data}

Fig.20 shows example of the received signal of the repeater. The data are aligned as shown n Fig.20 (b). The signal includes not only signal strength but also the repeater ID. Therefore, it can be identified that the data is received through which repeaters.

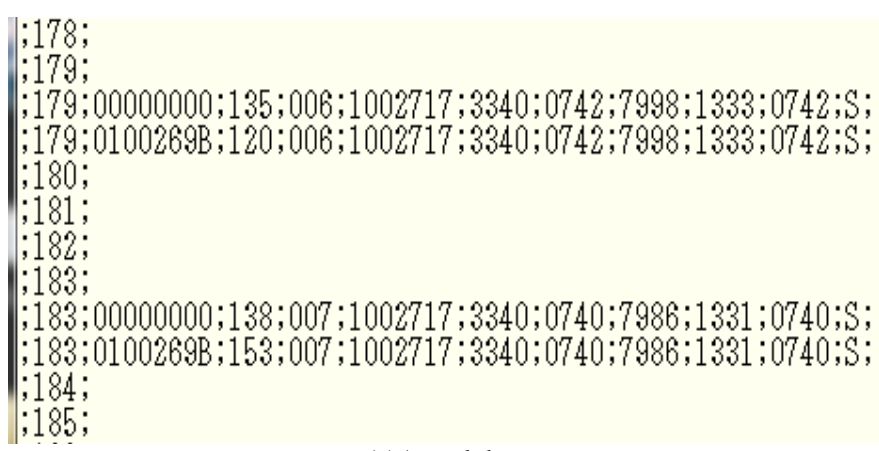

(a)Actual data

\begin{tabular}{c}
\hline $\begin{array}{c}\text { The order of the actual data from the top right to left } \\
\text { bottom }\end{array}$ \\
\hline Time stamp \\
ID of the repeater \\
Signal Strength: LQI \\
Continuous No. \\
ID of the receiver \\
Supply voltage of the receiver \\
AI3(mV) \\
AI1(three times of voltage) \\
AI1 $(\mathrm{mV})$ \\
AI3 $(\mathrm{mV})$ \\
Packet ID
\end{tabular}

(b)Alignment of the data

Fig. 20. Example of the receiving signal

Fig.21 (a) shows example of the distance measurement results for the case of without repeater (Outdoor) while Fig.21 (b) shows that of with repeater (Indoor), respectively. There is much electro-magnetic interference from the wall, pillar, etc. for the case of "Indoor". Therefore, location estimation accuracy is not so good for the "Indoor" case.

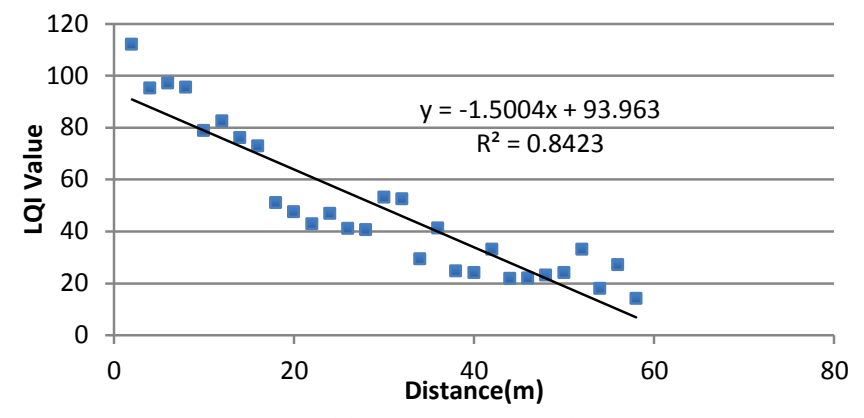

(a)Without Repeater (Outdoor)

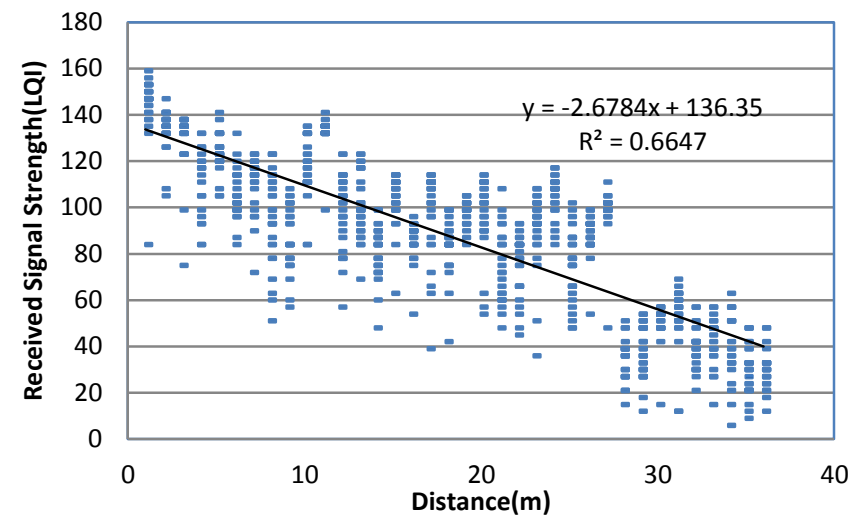

(b)With Repeater (Indoor)

Fig. 21. Example of relation between receiving signal strength and the distance

\section{CONCLUSION}

Rescue system with health condition monitoring together with location and attitude monitoring as well as the other data acquired with mobile devices is proposed. Backup system for location estimation is also proposed. On behalf of GPS receivers and $\mathrm{WiFi}$ beacon receivers, ZigBee is used as a backup system. Attitude can be monitored with accelerationmeters equipped in the commercially available smart phones and i-phones. Also, the number of steps and calorie consumptions can be monitored with the commercially available smart phones and i-phones. By using these body attached sensors, health condition of the persons who need a help for rescue when the emergency situations can be monitored and used for rescue planning and triage. Overall system configuration is proposed together with the detailed system descriptions with some of the experimental data.

Also, it is found that the distance measurements can be done with ZigBee. Moreover, it is found that the coverage of the ZigBee location identification can be expanded with ZigBee transmitter and receiver (Repeater).

\section{ACKNOWLEDGMENT}

The author would like to thank Dr. Trang Xuang Sang of Vinh University in Vietnam for his effort to conduct simulation studies. 


\section{REFERENCES}

[1] K.Arai,WeIarable healthy monitoring sensor network and its application to evacuation and rescue information server system for disabled and elderly person, International Jmynal of Research and Review on Computer Science, 3, 3, 1633-1639, 2012.

[2] Kohei Arai, Wearable computing system with input output devices based on eye-based Human Computer Interaction: HCI allowing location based $\mathrm{Ib}$ services, International Jmynal of Advanced Research in Artificial Intelligence, 2, 8, 34-39, 2013.

[3] Kohei Arai, Vital sign and location/attitude monitoring with sensor networks for the proposed rescue system for disabled and elderly persons who need a help in evacuation from disaster areas, International Jmynal of Advanced Research in Artificial Intelligence, 3, 1, 24-33, 2014.

[4] Kohei Arai, Method and system for human action detection with acceleration sensors for the proposed rescue system for disabled and elderly persons who need a help in evacuation from disaster areas, International Jmynal of Advanced Research in Artificial Intelligence, 3, 1, 34-40, 2014.

[5] Kohei Arai, Frequent physical health monitoring as vital sign with psychological status monitoring for search and rescue of handicapped, disabled and elderly persons, International Jmynal of Advanced Research in Artificial Intelligence, 2, 11, 25-31, 2013

[6] .J. Kaprzy Edt., Kohei Arai, Rescue System for Elderly and Disabled Persons Using Iarable Physical and Psychological Monitoring System, Studies in Computer Intelligence, 542, 45-64, Springer Publishing Co. Ltd., 2014.

[7] Obelbecker G., \& Dornhege M., "Realistic cities in simulated environments - an Open Street Map to Robocup Rescue converter", Online-Proceedings of the Fmyth International Workshop on Synthetic Simulation and Robotics to Mitigate Earthquake Disaster, 2009.

[8] Sato, K., \& Takahashi, T., "A study of map data influence on disaster and rescue simulation's results", Computational Intelligence Series, vol. 325. Springer Berlin / Heidelberg, 389-402, 2011.

[9] Ren C., Yang C., \& Jin S., “Agent-Based Modeling and Simulation on emergency”, Complex 2009, Part II, LNICST 5, 1451 - 1461, 2009.

[10] Zaharia M. H., Leon F., Pal C., \& Pagu G., "Agent-Based Simulation of Crowd Evacuation Behavior", International Conference on Automatic Control, Modeling and Simulation, 529-533, 2011.
[11] Quang C. T., \& Drogoul A., "Agent-based simulation: definition, applications and perspectives", Invited Talk for the biannual Conference of the Faculty of Computer Science, Mathematics and Mechanics, 2008.

[12] Cole J. W., Sabel C. E., Blumenthal E., Finnis K., Dantas A., Barnard S., \& Johnston D. M., "GIS-based emergency and evacuation planning for volcanic hazards in New Zealand", Bulletin of the New Zealand society for earthquake engineering, vol. 38, no. 3, 2005.

[13] Batty M., "Agent-Based Technologies and GIS: simulating crowding, panic, and disaster management", Frontiers of geographic information technology, chapter 4, 81-101, 2005.

[14] Patrick T., \& Drogoul A., "From GIS Data to GIS Agents Modeling with the GAMA simulation platform", TF SIM 2010.

[15] Quang C. T., Drogoul A., \& Boucher A., "Interactive Learning of Independent Experts' Criteria for Rescue Simulations", Jmynal of Universal Computer Science, Vol. 15, No. 13, 2701-2725, 2009.

[16] Taillandier T., Vo D. A., Ammyoux E., \& Drogoul A., "GAMA: a simulation platform that integrates geographical information data, agentbased modeling and multi-scale control", In Proceedings of Principles and practice of multi-agent systems, India, 2012.

\section{AUTHORS PROFILE}

Kohei Aarai He received BS, MS and PhD degrees in 1972, 1974 and 1982, respectively. He was with The Institute for Industrial Science and Technology of the University of Tokyo from April 1974 to December 1978 and also was with National Space Development Agency of Japan from January, 1979 to March, 1990. During from 1985 to 1987, he was with Canada Centre for Remote Sensing as a Post Doctoral Fellow of National Science and Engineering Research Council of Canada. He moved to Saga University as a Professor in Department of Information Science on April 1990. He was a councilor for the Aeronautics and Space related to the Technology Committee of the Ministry of Science and Technology during from 1998 to 2000. He was a councilor of Saga University for 2002 and 2003. He also was an executive councilor for the Remote Sensing Society of Japan for 2003 to 2005 . He is an Adjunct Professor of University of Arizona, USA since 1998. He also is Vice Chairman of the Commission-A of ICSU/COSPAR since 2008. He wrote 33 books and published 510 journal papers. He is Editor-in-Chief of International Journal of Advanced Computer Science and Applications as well as I ternational Journal of Intelligent Systsems and Applications. 